\title{
Generation of Singlet Oxygen by Persistent Luminescent Nanoparticle-Photosensitizer Conjugates: A Proof of Principle for Photodynamic Therapy without Light
}

\author{
Tugba Ozdemir ${ }^{+},{ }^{[a]}$ Yu-Chen $\mathrm{Lu}^{+}{ }^{[b]}$ Safacan Kolemen, ${ }^{[a]}$ Esra Tanriverdi-Ecik, ${ }^{[c]}$ and \\ Engin U. Akkaya ${ }^{*[a, d]}$
}

\begin{abstract}
The broader application of photodynamic therapy as a treatment procedure for cancer is hampered by the limited penetration of light through mammalian tissues. Since the photosensitized generation of cytotoxic singlet oxygen requires effective excitation of the tumor-localized photosensitizer, photodynamic action can only be guaranteed for the first few millimeters of the irradiated tissues. In this work, we demonstrated that the phenomenon of persistent luminescence, that is, delayed emission from certain metal-ion excited states (with crystal defects acting as energy traps), can provide an alternative excitation possibility. Thus, persistent luminescent nanoparticles functionalized by FRET-matching Bodipy sensitizers (FRET = Förster resonance energy transfer) were excited in situ before administration into a cell culture or an organism. It was found that this system continues to produce singlet oxygen regardless of their location and without any need for continuous photonic excitation.
\end{abstract}

Photodynamic therapy (PDT) of cancer, which is based on the photosensitized generation of singlet oxygen in tumor tissues, has attracting renewed interest in recent years. ${ }^{[1-4]}$ Unlike the previous decades, most of this recent work is focused on the selective activation of photosensitizers and the precise delivery of the cytotoxic agent, singlet oxygen, rather than the synthesis of newer photosensitizers. ${ }^{[5-13]}$ However, there are a few lin-

[a] Dr. T. Ozdemir, ${ }^{+}$Dr. S. Kolemen, Prof. E. U. Akkaya

UNAM-Institute of Material Science and Nanotechnology

Bilkent University

Ankara 06800 (Turkey)

E-mail: eua@fen.bilkent.edu.tr

[b] Y.-C. Lu H $^{+}$

Research Center for Analytical Science

College of Chemistry and Nano Science

Nankai University

94 Weijin Road, Tianjin 300071 (P.R. China)

[c] Dr. E. Tanriverdi-Ecik

Department of Chemistry

Gebze Technical University

Kocaeli 41400 (Turkey)

[d] Prof. E. U. Akkaya

Department of Chemistry

Bilkent University

Ankara 06800 (Turkey)

$\left.{ }^{+}\right]$These authors contributed equally to this work.

$\square$ Supporting Information and the ORCID identification number(s) for the

(iD

author(s) of this article can be found under:

http://dx.doi.org/10.1002/cptc.201600049. gering problems associated with PDT which hinder its development into a broadly applicable therapeutic procedure. ${ }^{[14-16]}$ One of these problems is the issue of light penetration through tissues. ${ }^{[17]}$ Although the term "therapeutic window" implies that light with a wavelength in the $\lambda=650-800 \mathrm{~nm}$ range is more penetrating inside mammalian tissues, a closer inspection reveals that even at these optimal wavelengths, effective penetration is limited to a few millimeters. ${ }^{[18]}$ This would limit the applicability to superficial lesions.

We surmised that materials with a long afterglow may offer a solution, eliminating altogether the need for external excitation. Naturally, most appropriate materials for this purpose would be persistent luminescent nanoparticles (PLNP). There has been considerable progress in the design of such materials. ${ }^{[19-24]}$ Some of these systems have even been proposed as in vivo imaging agents. ${ }^{[25-34]}$ Persistence luminescence is an interesting phenomenon resulting from the embedding of metal ions in certain inorganic matrices with particular energy-trap states, which can relax by thermal equilibration or photonic emission with emissive states of other ions present in the same matrix. ${ }^{[3,35]}$ Compared to bulk persistent luminescent materials, nanoparticles are less emissive as a result of the relative increase in the defect structures. ${ }^{[26]}$ Nevertheless, efficient energy transfer to dyes on PLNPs have been amply documented. ${ }^{[32,34]}$

Our proposed design concept is shown schematically in Figure 1. Thus, excitation of the photosensitizer-functionalized PLNPs can be done outside of the biological medium (in vivo or in vitro), and then transferred to the location of the tumor. As result of the long afterglow, or in this case, delayed energy transfer, the energy of the excited ionic species in the PLNPs will be transferred to the photosensitizer (PS) in the dark, and most likely, even minutes after the UV irradiation has stopped. Generation of singlet oxygen inside the tumor would lead to apoptosis and cell death, as it takes place in regular PDT. ${ }^{[36-39]}$ The great advantage here would be the fact that once the (1)PLNP conjugate is activated by irradiation, it will be capable of producing singlet oxygen regardless of the depth of the tumor.

The zinc-germanogallate-based PLNP sample used in this study was previously characterized and reported ${ }_{r}^{[40]}$ with the preparation procedure involving a citrate sol-gel method followed by calcination. The intensity and the persistence of the PLNP emission were improved by co-doping with $\mathrm{Pr}^{3+} / \mathrm{Cr}^{3+}$. The PLNPs had a composition of $\mathrm{Zn}_{2.78} \mathrm{Ga}_{1.68} \mathrm{Ge}_{1.00} \mathrm{O}_{8}: \mathrm{Cr}_{0.01}, \mathrm{Pr}_{0.02}$ based on X-ray fluorescence spectrometry. The average size of 


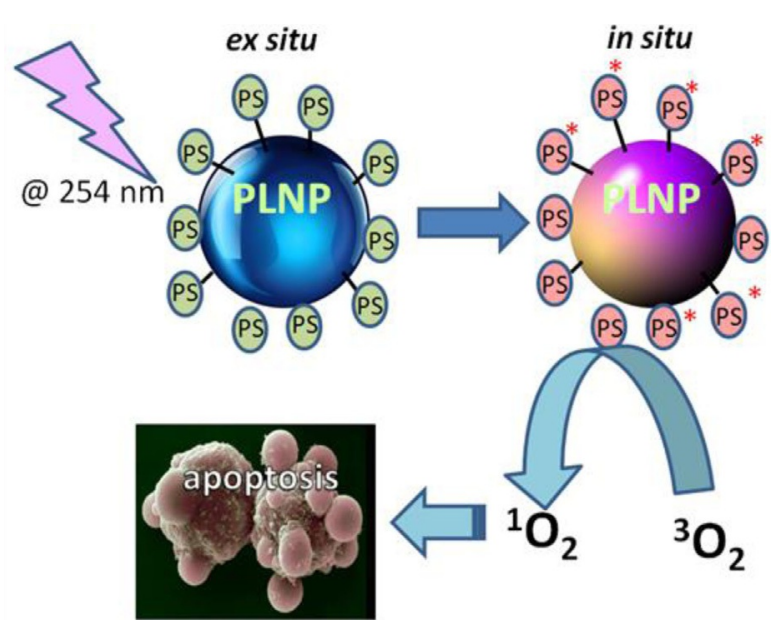

Figure 1. Ex situ "charging" of the PLNP by UV irradiation, followed by energy-transfer excitation of the tethered photosensitizers (PS), leads to singlet oxygen generation in situ long after the excitation source is turned off and PLNPs have been transferred to a different locale (cell culture or a tumor model).

the NPs were approximately $50 \mathrm{~nm}$ based on TEM, with hydrodynamic diameter of $70 \mathrm{~nm}$ calculated on the basis of dynamic light scattering (DLS) data. The luminescence band maximum of the nanoparticles occurred at $\lambda=695 \mathrm{~nm}$. The PLNPs were then coated by the reaction of 3-aminopropyltriethoxysilane (APTES) with the surface hydroxy groups on the PLNPs.

In order to experimentally investigate the premise of this work, we targeted compound $\mathbf{1}$ as the photosensitizer (Figure 2). Here, to ensure an efficient energy-transfer from

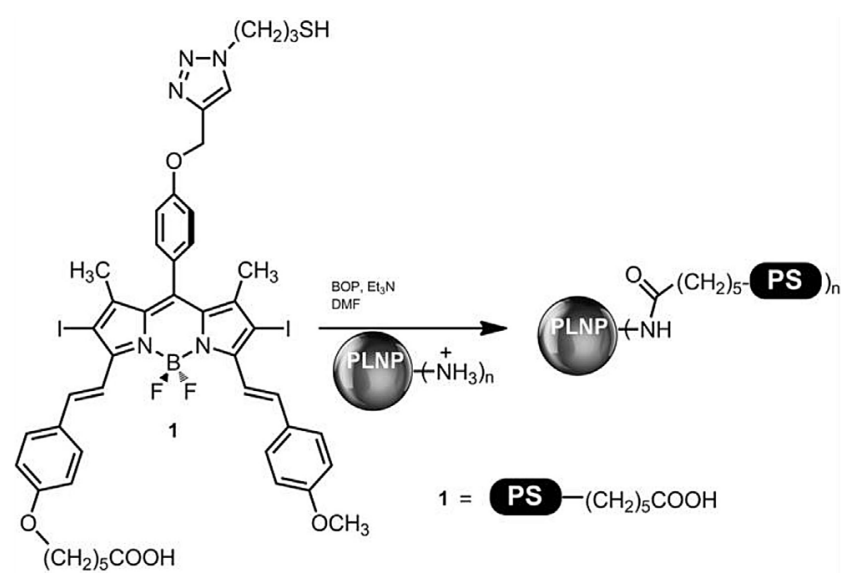

Figure 2. The structure and synthesis of the (1)-PLNP conjugate.

PLNP to compound 1, a long-wavelength-absorbing Bodipy dye (distyryl-Bodipy) ${ }^{[41]}$ that has significant spectral overlap with the PLNP emission was selected. Heavy atoms (iodines) were placed on the Bodipy chromophore to facilitate intersystem crossing to the triplet manifold for an efficient singlet oxygen generation. ${ }^{[42,43]}$ A meso-substituent was chosen for potential further derivatization. The 3-position of the Bodipy core carries an aliphatic carboxylic acid function, placed for straight- forward conjugation to amine-modified PLNPs. Compound 1 was synthesized in nine steps from commercially available materials (detailed procedures and the synthetic scheme are available in the Supporting Information). The coupling reaction of the carboxylic acid functionalized photosensitizer 1 to the amino-ligated PLNP was carried out in DMF using BOP as a reagent $\quad(B O P=$ benzotriazol-1-yloxy)tris-(dimethylamino)-phosphonium hexafluorophosphate). The (1)-PLNP conjugated nanoparticles were purified by centrifugation and washing.

The singlet-oxygen generation capacity of the (1)-PLNP conjugates was first investigated by looking for singlet-oxygen phosphorescence at $\lambda=1270 \mathrm{~nm}$ following UV excitation of the nanoparticles. The data unequivocally shows that bare PLNPs do not generate singlet oxygen, whereas the (1)-PLNP conjugate show the characteristic phosphorescence band (see the Supporting Information). Further experiments with the selective singlet-oxygen trap compound 2'-(anthracene-9,10-diylbis(methylene))dimalonic (ADMDA) in aqueous solutions (Figure 3 ) also corroborate the activity of the (1)-PLNP conjugate for singlet-oxygen generation.

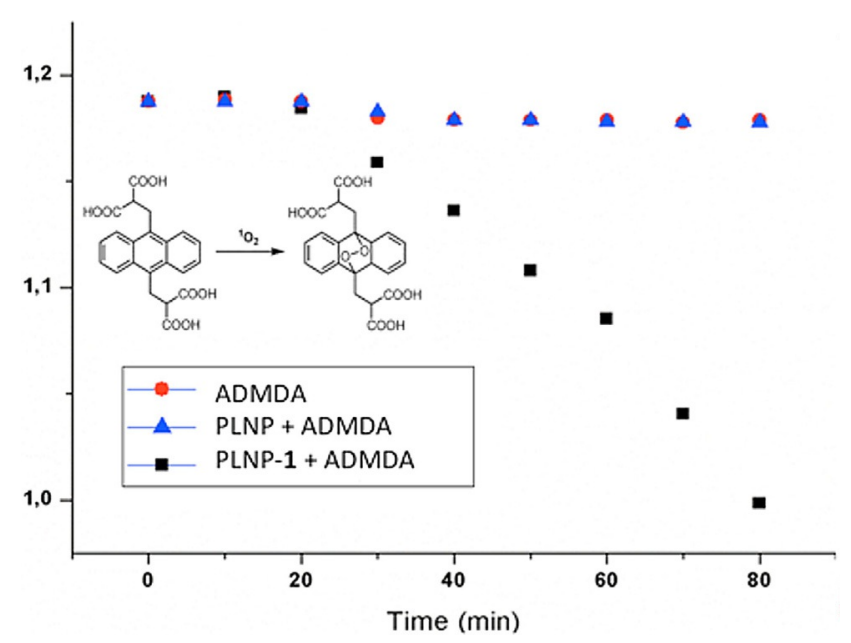

Figure 3. Relative singlet-oxygen efficiency of just the trap (red circles), PLNP alone (blue triangles) and the (1)-PLNP conjugate (black squares) in aqueous solutions. The efficiency was detected by the absorbance intensity decrease of ADMDA at $\lambda=376 \mathrm{~nm}$ with time. During the first $20 \mathrm{~min}$, the samples were kept in the dark and for the following $60 \mathrm{~min}$, the samples were irradiated with $254 \mathrm{~nm}$ light using a UV lamp.

In order to confirm that singlet-oxygen generation continues in darkness, we carried out the following experiment: Instead of following absorbance changes, the ${ }^{1} \mathrm{O}_{2}$ generation capability of (1)-PLNP was examined by recording the decrease in fluorescence emission of the singlet-oxygen probe 1,3-diphenylisobenzofuran (DPBF; Figure 4). In a typical experiment, the solvent acetonitrile was bubbled with air for $30 \mathrm{~min}$ to ensure the availability of dissolved oxygen during ${ }^{1} \mathrm{O}_{2}$ detection. Then, the DPBF ( $200 \mu \mathrm{L}, 20 \mu \mathrm{M}$ in acetonitrile) was added to the dispersion of pre-excited $(254 \mathrm{~nm}, 6 \mathrm{~W})$ (1)-PLNP $(2 \mathrm{~mL}$, $1 \mathrm{mg} \mathrm{mL}^{-1}$ ) in the dark. The fluorescence of DPBF at $\lambda=$ $480 \mathrm{~nm}$ was recorded at two minute intervals $\left(\lambda_{\mathrm{ex}}=410 \mathrm{~nm}\right)$. The results (Figure 4) clearly indicate that singlet oxygen pro- 


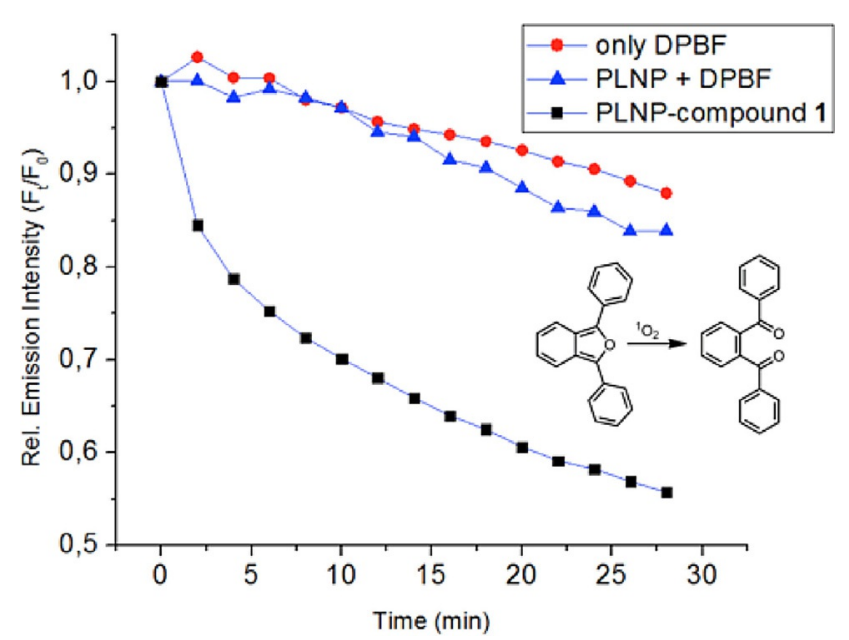

Figure 4. Persistent-luminescence-sensitized generation of ${ }^{1} \mathrm{O}_{2}$. The time course of the relative fluorescence emission intensity change of DPBF monitoring emission at $\lambda=480 \mathrm{~nm}$ caused by the generation of ${ }^{1} \mathrm{O}_{2}$ in the dark was monitored. The PLNP-compound 1 or the bare-PLNPs were pre-excited at $254 \mathrm{~nm}$ for $5 \mathrm{~min}$ before addition of DPBF in acetonitrile. $F_{0}$ is the DPBF emission intensity at $t=0$. duction continues in darkness only for the PLNP-Bodipy compound 1 conjugate.

Cell culture studies were done using HepG2 cells. The cells were incubated with PLNP (Bare PLNPs) or (1)-PLNP and subjected to UV irradiation at $254 \mathrm{~nm}$ for $5 \mathrm{~min}$ (Figure 5). Without irradiation, the cells showed no staining with fluorescein-labeled Annexin V (FITC-Annexin V). This indicates that there is no apoptotic cell death under those conditions, as FITC-Annexin $\mathrm{V}$ is a specific marker of phosphatidylserine flipped to the outer leaf of the cellular membrane during apoptosis. ${ }^{[44]}$ The situation is not much different with PNLP and UV light exposure. Only when (1)-PLNP derivative was used, significant Annexin $\mathrm{V}$ labeling and propidium iodide (PI) staining was observed. PI enters the cells only when membrane integrity is severely compromised, another indication of cell death.

In order to quantify the effectiveness of the applied methodology, standard MTT assays were carried out. In Figure 6, the surviving fraction of the HepG2 cells was shown as a function of the concentration of the agent used. As expected, UV irradiation and PLNPs alone result in some cell death under the experimental conditions. However, the cytotoxic effect is significantly enhanced when (1)-PLNP conjugates were used.

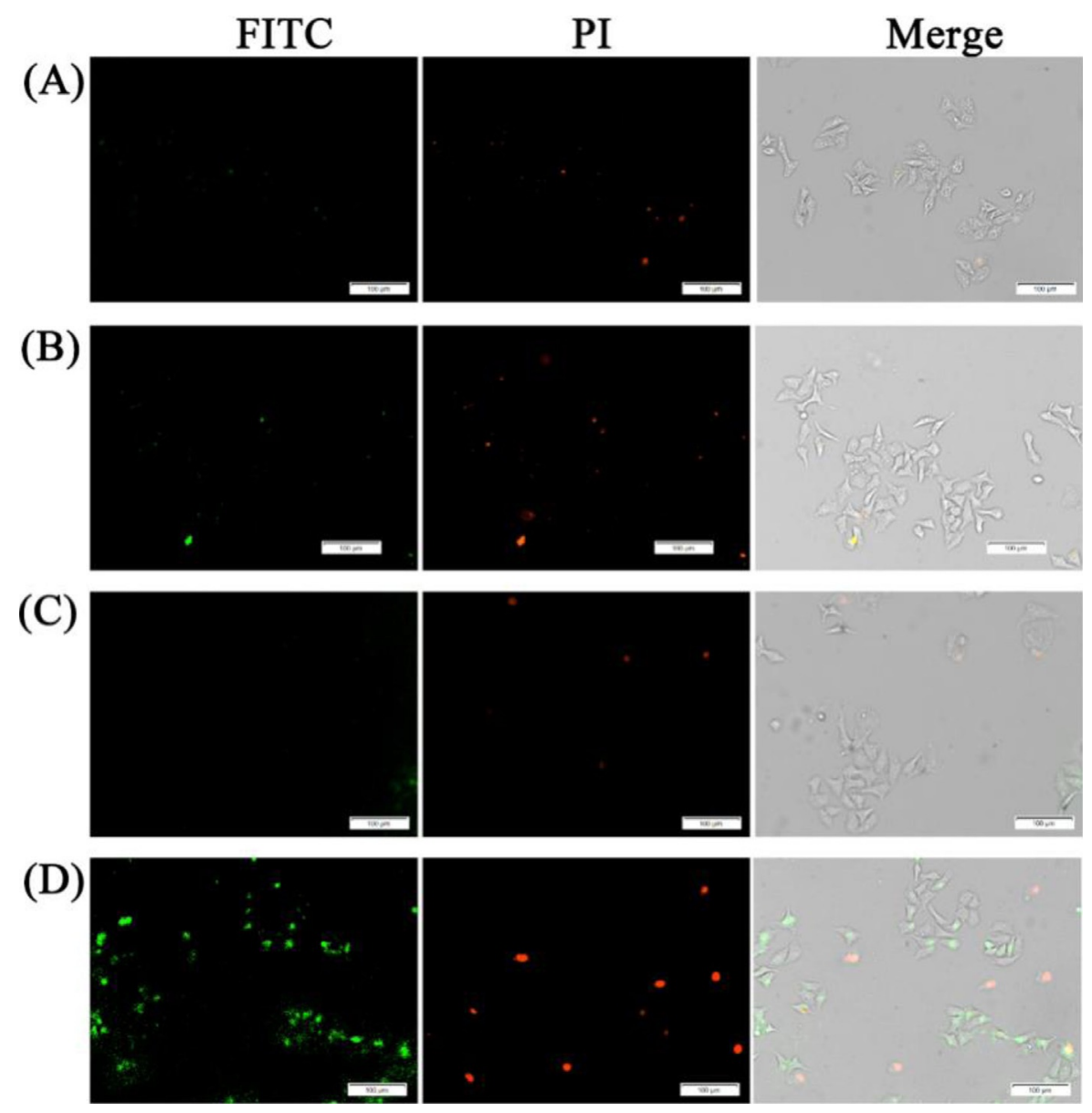

Figure 5. (1)-PLNP induced cell apoptosis as determined by fluorescence imaging using Annexin V-FITC/PI staining on HepG2 cells. A) HepG2 cells with BarePLNP (200 $\mathrm{g} \mathrm{mL}^{-1}$ ) treatment and without irradiation. B) HepG2 cells incubated with Bare-PLNP (200 $\mu \mathrm{g} \mathrm{mL}^{-1}$ ) and exposed to UV light for $5 \mathrm{~min}$. C) HepG2 cells treated with (1)-PLNP (200 $\left.\mu \mathrm{g} \mathrm{mL}^{-1}\right)$ without irradiation. D) HepG2 cells incubated with (1)-PLNP (200 $\left.\mu \mathrm{g} \mathrm{mL}{ }^{-1}\right)$, and exposed to UV light for $5 \mathrm{~min}$. Scale bar $=100 \mu \mathrm{m}$. 


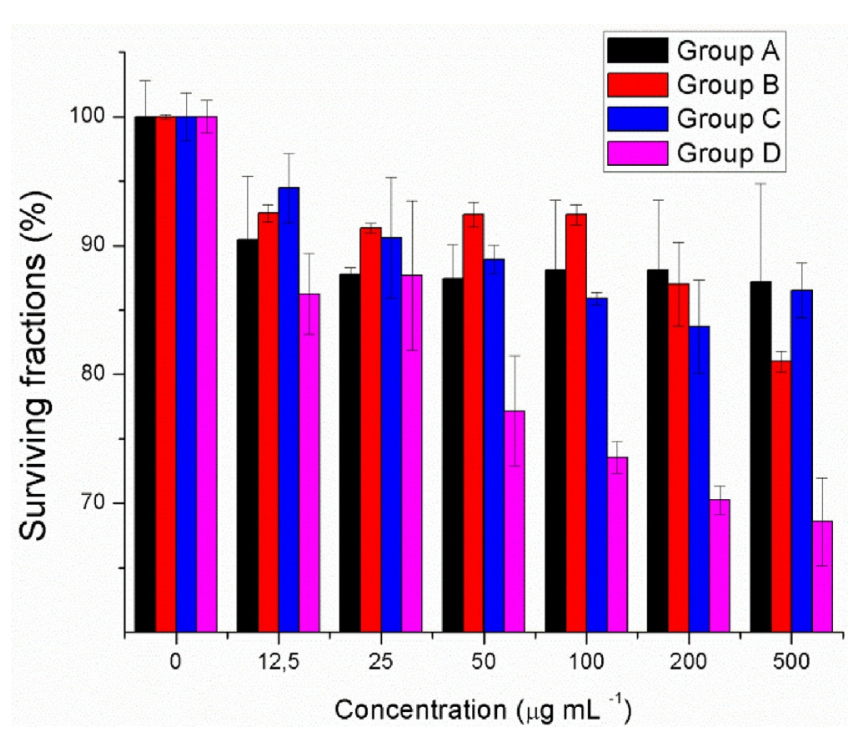

Figure 6. MTT assays (performed after $24 \mathrm{~h}$ ): Surviving fractions of HepG2 cells incubated with Bare-PLNP for $8 \mathrm{~h}$, followed by UV light irradiation ( $5 \mathrm{~W}$, $254 \mathrm{~nm}$ ). A) HepG2 cells with Bare-PLNP treatment, without irradiation. B) HepG2 cells incubated with Bare-PLNP, exposed to UV light for $5 \mathrm{~min}$. C) HepG2 cells treated with (1)-PLNP, without irradiation. D) HepG2 cells incubated with (1)-PLNP, exposed to UV light for $5 \mathrm{~min}$. Data correspond to mean \pm S.D. values.

The PDT efficacy of the (1)-PLNP conjugate was investigated using tumor-bearing mice models (adult athymic BALB/c mice). Tumor-bearing mice were established by subcutaneous inoculation of a HepG2 cell suspension ( $5 \times 10^{6}$ cells per mouse) into the flank region of 3-4-week-old male nude mice. The experiment included two groups for comparison: Bare PNLP-NH with irradiation as the control, and Bodipy-conjugated (1)PLNP conjugate as the experiment group. The nanoparticles solutions $\left(40 \mu \mathrm{L}, 15 \mathrm{mg} \mathrm{mL}^{-1}\right.$ in PBS at $\left.\mathrm{pH} 7.4\right)$ were irradiated with a UV lamp for $2 \mathrm{~min}$ at $254 \mathrm{~nm}$ before they were injected intratumorally to mice. The nanoparticles were injected into the tumor site every $24 \mathrm{~h}$ for 10 days after pre-excitation under UV light irradiation.

To evaluate the therapeutic efficacy, tumor growth was monitored, measuring the tumor size with a digital caliper. On day 11 , a modest but statistically significant reduction in tumor volume $(15 \%)$ was recorded.

Considering the fact that the PLNP afterglow was short, it is not surprising that the in vivo PDT effect is modest. However, persistence luminescence is a vibrant field, thus new and longer afterglow nanoparticles are expected. On the other hand, singlet-oxygen trap experiments, cell culture and MTT experiments all validated our proposal, and as a proof of principle, the (1)-PLNP conjugate was shown to function in accordance with the design parameters. Needless to say, we expect further work along this line to bring more persistent generators of singlet oxygen in the dark. It is also possible to block the singlet-oxygen generation by a disulfide-tethered quencher, which would be cleaved under the reductive conditions of the tumors. Thus, this proof of principle may offer a unique potential for addressing a persistent problem of PDT. Our work in that direction is in progress.

\section{Note on Animal Experiments Described herein:}

Animal treatment and maintenance were performed in accordance with the Principle of Laboratory Animal Care (NIH Publication number 85-23, revised 1985). All animals were treated in accordance with the guidelines of the Committee on Animals of Nankai University (Tianjin, Peoples' Republic of China). All animal procedures were approved by the Nankai University Experimental Animal Ethics Committee.

\section{Acknowledgements}

E.U.A. gratefully acknowledges support from Bilkent University. E.T.-E. is grateful for a postdoctoral scholarship from TUBITAK.

\section{Conflict of interest}

The authors declare no conflict of interest.

Keywords: nanoparticles - persistent luminescence photodynamic therapy $\cdot$ photosensitizers $\cdot$ singlet oxygen

[1] S. Ozlem, E. U. Akkaya, J. Am. Chem. Soc. 2009, 131, 48-49.

[2] I. Simsek Turan, D. Yildiz, A. Turksoy, G. Gunaydin, E. U. Akkaya, Angew. Chem. Int. Ed. 2016, 55, 2875-2878; Angew. Chem. 2016, 128, 2925 2928.

[3] S. Kolemen, T. Ozdemir, D. Lee, G. M. Kim, T. Karatas, J. Yoon, E. U. Akkaya, Angew. Chem. Int. Ed. 2016, 55, 3606-3610; Angew. Chem. 2016, 128, 3670-3674.

[4] Y. Cakmak, S. Kolemen, S. Duman, Y. Dede, Y. Dolen, B. Kilic, Z. Kostereli, L. T. Yildirim, A. L. Dogan, D. Guc, E. U. Akkaya, Angew. Chem. Int. Ed. 2011, 50, 11937-11941; Angew. Chem. 2011, 123, 12143-12147.

[5] M. Bio, P. Rajaputra, G. Nkepang, Y. You, J. Med. Chem. 2014, 57, 3401 3409.

[6] A. Shao, Y. Xie, S. Zhu, Z. Guo, S. Zhu, J. Guo, P. Shi, T. D. James, H. Tian, W. H. Zhu, Angew. Chem. Int. Ed. 2015, 54, 7275-7280; Angew. Chem. 2015, 127, 7383-7388.

[7] S. Erbas-Cakmak, E. U. Akkaya, Angew. Chem. Int. Ed. 2013, 52, $11364-$ 11368; Angew. Chem. 2013, 125, 11574-11578.

[8] I. Simsek-Turan, F. Pir-Cakmak, D. C. Yildirim, R. Cetin-Atalay, E. U. Akkaya, Chem. Eur. J. 2014, 20, 16088-16092.

[9] S. Kolemen, M. Isik, G. M. Kim, D. Kim, H. Geng, M. Buyuktemiz, T. Karatas, X.-F. Zhang, Y. Dede, J. Yoon, E. U. Akkaya, Angew. Chem. Int. Ed. 2015, 54, 5340-5344; Angew. Chem. 2015, 127, 5430-5434.

[10] B. Wang, H. Yuan, Z. Liu, C. Nie, L. Liu, F. Lv, Y. Wang, S. Wang, Adv. Mater. 2014, 26, 5986-5990.

[11] E. J. Kim, S. Bhuniya, H. Lee, H. M. Kim, C. Cheong, S. Maiti, K. S. Hong, J. S. Kim, J. Am. Chem. Soc. 2014, 136, 13888-13894.

[12] G. Kong, G. Anyarambhatla, W. P. Petros, R. D. Braun, O. M. Colvin, D. Needham, M. W. Dewhirst, Cancer Res. 2000, 60, 6950-6957.

[13] N. Huebsch, C. J. Kearney, X. Zhao, J. Kim, C. A. Cezar, Z. Suo, D. J. Mooney, Proc. Natl. Acad. Sci. USA 2014, 111, 9762-9767.

[14] R. Sullivan, C. H. Graham, Cancer Metastasis Rev. 2007, 26, 319-331.

[15] J. A. Bertout, S. A. Patel, M. C. Simon, Nat. Rev. Cancer 2008, 8, 967-975.

[16] T. M. Busch, S. M. Hahn, S. M. Evans, C. J. Koch, Cancer Res. 2000, 60, $2636-2642$.

[17] S. Stolik, J. A. Delgado, A. Perez, L. Anasagasti, J. Photochem. Photobiol. B 2000, 57, 90-93.

[18] W. J. Cheong, S. A. Prahl, A. J. Welch, IEEE J. Quantum Electron. 1990, 26, $2166-2185$.

[19] J. Hölsä, Electrochem. Soc. Interf. 2009, 18, 42-45.

[20] W. M. Yen, S. Shionoya, H. Yamamoto, Phosphor Handbook, CRC Press, Boca Raton, FL, 2007. 
[21] T. Aitasaloa, P. Dereńc, J. Hölsäa, H. Jungnerd, J.-C. Krupae, M. Lastusaaria, J. Legendziewiczf, J. Niittykoskia, W. Strękc, J. Solid State Chem. 2003, 171, 114-122

[22] T. Matsuzawa, Y. Aoki, N. Takeuchi, Y. Murayama, J. Electrochem. Soc. 1996, 143, 2670-2673.

[23] W. Chen, J. Zhang, J. Nanosci. Nanotechnol. 2006, 6, 1159-1166.

[24] K. Van den Eeckhout, P. F. Smet, D. Poelman, Materials 2010, 3, 2536 2566.

[25] Q. le Masne de Chermont, C. Chaneac, J. Seguin, F. Pelle, S. Maitrejean, J. P. Jolivet, D. Gourier, M. Bessodes, D. Scherman, Proc. Natl. Acad. Sci. USA 2007, 104, 9266-9271.

[26] T. Maldiney, C. Richard, J. Seguin, N. Wattier, M. Bessodes, D. Scherman ACS Nano 2011, 5, 854-862.

[27] T. Maldiney, A. Lecointre, B. Viana, A. Bessiere, M. Bessodes, D. Gourier, C. Richard, D. Scherman, J. Am. Chem. Soc. 2011, 133, 11810-11815.

[28] T. Maldiney, M. U. Kaikkonen, J. Seguin, Q. le Masne de Chermont, M. Bessodes, K. J. Airenne, S. Yla-Herttuala, D. Scherman, C. Richard, Opt Mater. Express 2012, 2, 261-268.

[29] F. Liu, W. Yan, Y.-J. Chuang, Z. Zhen, J. Xie, Z. Pan, Sci. Rep. 2013, 3, 1554.

[30] T. Maldiney, M. U. Kaikkonen, J. Seguin, Q. le Masne de Chermont, M. Bessodes, K. J. Airenne, S. Ylä-Herttuala, D. Scherman, C. Richard, Bioconjugate Chem. 2012, 23, 472-478.

[31] T. Maldiney, G. Byk, N. Wattier, J. Seguin, R. Khandadash, M. Bessodes, C. Richard, D. Scherman, Int. J. Pharm. 2012, 423, 102-107.

[32] B.-Y. Wu, H.-F. Wang, J.-T. Chen, X.-P. Yan, J. Am. Chem. Soc. 2011, 133, $686-688$
[33] Z.-J. Li, H.-W. Zhang, M. Sun, J.-S. Shen, H.-X. Fu, J. Mater. Chem. 2012 $22,24713-24720$

[34] T. Maldiney, A. Bessière, J. Seguin, E. Teston, S. K. Sharma, B. Viana, A. J. J. Bos, P. Dorenbos, M. Bessodes, D. Gourier, D. Scherman, C. Richard, Nat. Mater. 2014, 13, 418-426.

[35] Z. Pan, Y.-Y. Lu, F. Liu, Nat. Mater. 2012, 11, 58-63.

[36] P. Mroz, A. Yaroslavsky, G. B. Kharkwal, M. R. Hamblin, Cancers 2011, 3, $2516-2539$.

[37] D. E. Dolmans, D. Fukumura, R. K. Jain, Nat. Rev. Cancer 2003, 3, $380-$ 387.

[38] T. J. Dougherty, J. E. Kaufman, A. Goldfarb, K. R. Weishaupt, D. Boyle, A. Mittleman, Cancer Res. 1978, 38, 2628-2635.

[39] J. Moan, Q. Peng, Anticancer Res. 2003, 23, 3591-3600.

[40] A. Abdukayum, J.-T. Chen, Q. Zhao, X.-P. Yan, J. Am. Chem. Soc. 2013, $135,14125-14133$.

[41] A. Loudet, K. Burgess, Chem. Rev. 2007, 107, 4891-4932.

[42] A. Gorman, J. Killoran, C. O'Shea, T. Kenna, W. M. Gallagher, D. F. O'Shea, J. Am. Chem. Soc. 2004, 126, 10619- 10631.

[43] T. Yogo, Y. Urano, Y. Ishitsuka, F. Maniwa, T. Nagano, J. Am. Chem. Soc 2005, 127, $12162-12163$.

[44] I. Vermes, C. Haanen, H. Steffens-Nakken, C. P. Reutelingsperger. J. Immunol. Methods 1995, 184, 39-51.

Manuscript received: December 24, 2016

Accepted Article published: February 16, 2017

Final Article published: March 29, 2017 